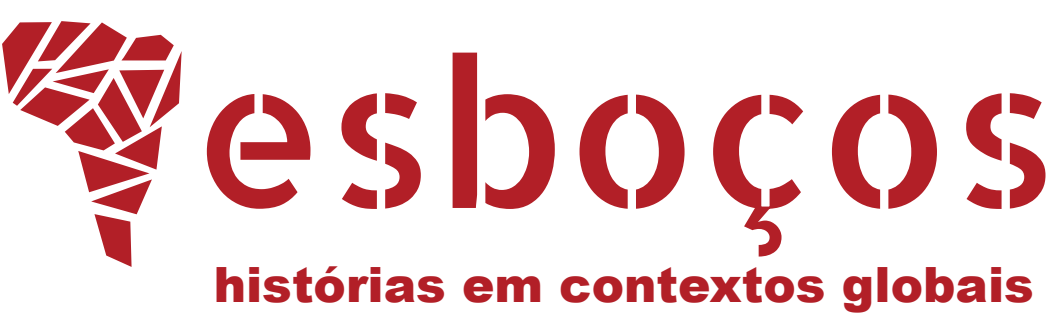

\title{
(CON)FIGURAÇÕES DO HISTORIADOR EM UM TEMPO MARCADO PELA DISRUPÇÃO TECNOLÓGICA
}

Historians' (con)figurations in times marked by technological disruption 


\title{
RESUMO
}

O presente artigo tem por objetivo observar algumas das práticas que podem ser incorporadas pelos historiadores ante as possibilidades da chamada "era digital". Analisamos, em parte, a relação das ciências humanas com os computadores, entendendo-a como um exercício de entusiasmo e de conservação, na medida em que as tecnologias são tomadas ora como uma potência de futuro, ora como a responsável pela dissolução do nosso campo profissional. Trabalhamos, também, com certas pressões sofridas pela disciplina histórica e o consequente anseio por se atualizar, tendo em vista o recente estudo de Valdei Araujo e Mateus Pereira acerca do "atualismo". A disrupção tecnológica parece estar formando novas identidades para a história e para os historiadores, sendo capaz de alargar as suas fronteiras e reinventar as suas tradições. Projetos criados para a internet, por exemplo, de canais no YouTube a podcasts, surgem como novas formas de atuação, e representam as (con)figurações do historiador em um tempo marcado pela inovação. Por fim, discutimos brevemente a disciplinação de novos campos ou movimentos teóricos, como são os casos das humanidades digitais e da história digital. Há razão em circunscrever o digital em limites disciplinares? Argumentamos que as recriações digitais do passado, estimuladas pelo que há de mais sofisticado no universo das novas tecnologias, devem inspirar a imaginação histórica, estando sempre desprendidas dos imperativos da disciplina.

\section{PALAVRAS-CHAVE}

História Digital. Humanidades digitais. Novas tecnologias.

\begin{abstract}
This article seeks to examine some practices that can be incorporated by historians considering the possibilities of the digital age. We analyze, on the one hand, the linkage between humanities and computers, understanding it as an exercise of enthusiasm and conservation, as far as technologies are either approached as future possibilities or held responsible for the dissolution of our professional field. We also address, on the other hand, certain pressures suffered by history as a discipline and the consequent desire for being updated, in view of a recent study by Valdei Araujo and Mateus Pereira regarding "updatism". Technological disruption seems to be shaping new identities for history and historians, while enlarging the frontiers of the history and reinventing its traditions. Internet projects, for example, from YouTube channels to podcasts, are emerging as new outlets for professional action and represent the (con)figurations of historians in times marked by innovation. Lastly, we briefly discuss the discipline of emerging theoretical fields or movements such as digital humanities and digital history. Is there any reason to restrict the digital sphere to disciplinary boundaries? We argue that digital recreations of the past, stimulated by highly sophisticated technologies, must inspire historical imagination, while remaining always untied to disciplinary imperatives.
\end{abstract}

\section{KEYWORDS}

Digital History. Digital humanities. New technologies. 
m um encontro casual com velhos amigos, parcerias semanais de uma boa cerveja, fui questionado sobre a minha própria profissão e a sua reação ante a internet. "Vocês devem estar pirando, né?", ouvi enquanto reparava a fumaça do quentão irromper na panela fervente. A interrogação me pegou de surpresa e rendeu uma longa discussão, sobre a qual voltarei mais adiante. Terminado o ensino médio, cada um dos meus companheiros seguiu um caminho diferente, das exatas à saúde, da filosofia às artes, razão pela qual sempre conversamos sobre os nossos cursos, nossa satisfação (ou não) com escolhas tomadas no calor da formatura, das provas finais, dos vestibulares. Independentemente da bebida nos copos, a pergunta sempre vem: "E aí, tá curtindo o curso?". Sempre respondo de maneira afirmativa, não sei se para evitar demonstrações de desgosto com a minha opção, defendê-la diante de pessoas que decidiram seguir trajetórias de maior prestígio, por áreas de grande notoriedade, enquanto eu, que sempre conquistei as melhores notas entre o meu grupo, agora estou preso em um mundo de incerto sucesso, quase sempre fadado aos baixos salários e ao desprezo do poder público. Evito tornar esse sentimento de injustiça uma evidência, e apenas revido com a mesma dúvida: "E tu, tá gostando das tuas aulas?". Acontece que, na ocasião que descrevi logo nas primeiras linhas, a conversa surgiu de outra forma. Já não queriam saber se eu estava me divertindo com algumas centenas de páginas de textos pouco atraentes, mas como eu e meus colegas de curso observamos o fenômeno da internet. Pela primeira vez em tantos encontros, o nosso bate-papo profissional ganhava contornos sólidos. A resposta não poderia ser a mesma de sempre, não seria sensato dizer que estava tudo bem, "nem pensamos muito sobre o assunto", "isso aí não é conosco", "sim, tô curtindo o curso". A discussão se estendeu por alguns bons minutos, o que nos obrigou a comer os restos gelados do jantar, quase inteiramente devorado por aqueles que, conscientemente ou não, se abstiveram da conversa que monopolizava a cozinha. Não saberia dizer se por formalismo, vício universitário ou pelo desespero com a produtividade científica, mas, já nas últimas gotas de saliva, o debate lentamente arrefecendo, pensei comigo mesmo que aquela conversa poderia virar um artigo. As páginas seguintes são, pois, uma tentativa de transformá-la em um texto acadêmico, com a infeliz ressalva de que o leitor não poderá acompanhá-lo com a cerveja, o quentão e os salgadinhos que energizavam o nosso palavratório.

Certa feita, em meio a tilintares e conversas paralelas do congresso anual da American Historical Association, um famoso historiador pregou a sua tese para o futuro da disciplina. De acordo com Anthony Grafton (2014), em uma curta entrevista para a History News Network, canal da Universidade George Mason no YouTube, a nova geração de historiadores será obrigada a incorporar competências informacionais. Deverá dominar códigos e linguagens de programação, e poderá perder o contato com fontes materiais, na medida em que passará a produzir livros em formato e plataformas digitais. Para Grafton, um intelectual da "velha guarda", professor universitário desde os anos 1970, os novos tempos exigirão da história a capacidade de se adaptar ao digital, habilidade que não fazia parte do repertório curricular que o formou há algumas boas décadas. Apesar da ênfase, Grafton não é o primeiro historiador a idealizar um futuro digital para a disciplina. Em 1968, na revista Le Nouvel Observateur, o francês Emmanuel Le Roy Ladurie afirmava que "o historiador de amanhã será programador 
ou não será". Essa crença, diga-se de passagem, deu forma ao seu mandato à frente da Biblioteca Nacional da França, entre 1987 e 1993, quando promoveu uma série de iniciativas de informatização de uma das principais instituições da intelectualidade francesa, inaugurando salas equipadas com computadores de última geração (LEMNY, 2017). Entre os prognósticos de Ladurie e Grafton, existe um intervalo de quase cinquenta anos. Centenas de historiadores e historiadoras formaram-se ao longo dessas décadas, diversos trabalhos foram publicados, variados debates tomaram conta da academia e transformaram as suas tradições. Porém, talvez nem sequer aconteça ainda o ensino de linguagens de programação em cursos de graduação e pós-graduação em história, e uma grande parcela da nossa comunidade permanece familiar aos empoeirados arquivos e às amareladas fontes históricas. Para a frustração de Ladurie, o historiador do seu futuro (ou seja, do nosso presente) não é um programador. No entanto, conjecturas como a sua ainda figuram entre o imaginário da disciplina, alimentadas pelo incessante desenvolvimento tecnológico que caracteriza o nosso tempo. Não à toa, apesar do revés do francês, Grafton insiste em projetar um futuro digital para a história e para os historiadores. As "novas tecnologias", que nunca parecem deixar de ser novidades, seguem sofisticando-se, seguem recebendo novas atualizações, seguem descontinuando velhos hábitos humanos e abrem alas a um porvir digno dos melhores livros e filmes sci-fi.

Profecias como essas não são de todo estranhas ao leitor atento às tendências do tempo histórico contemporâneo, marcado pelo fenômeno do atualismo (ARAUJO; PEREIRA, 2019). Munidos da ferramenta Google Ngram Viewer, ${ }^{1}$ Valdei Lopes de Araujo e Mateus Henrique de Faria Pereira (2019, p. 131-180) demonstram a derrocada de conceitos tipicamente modernos, como "revolução" e "progresso", em detrimento da dilatação da palavra "atualização" e suas variações. A partir de uma análise dos diversos usos dessa expressão que subitamente irrompe no bê-á-bá setentista, chegam à conclusão parcial de que "a pressão por estar atualizado ganha os contornos de uma ideologia, na medida em que parece dar sentido a uma visão conjunta da realidade" (ARAUJO; PEREIRA, 2019, p. 180). É como se fôssemos apartados da própria temporalidade, sendo necessário recuperar o seu passo, atualizar-se em razão da próxima novidade sob o risco da obsolescência. Parece impossível abdicar da sintonia com o que há de mais inovador, logo substituído por outra versão mais atualizada. O sentimento de ser/estar obsoleto é uma consequência imediata da superação pela própria temporalidade: o presente acelerou-se, tornou-se futuro e nos abandonou, como um sistema operacional desatualizado cujas funções permanecerão comprometidas até estar up to date. Cabe a observação de que se trata de um fenômeno, de marcas que nos atraem, não de um télos que nos consome, que reduz o humano às suas pretensões. O fato é que parece influenciar o pensamento de intelectuais como Ladurie e Grafton, entre tantos outros, e a sua percepção sobre o digital e a disciplina, como se ambos estivessem em plena assintonia. A história e os historiadores estão desatualizados, e a sua nova versão depende da incorporação de competências informacionais, do trato com dados e códigos com os quais não estamos habituados - ou melhor, que não nos foram apresentados ao longo de nossa formação, razão pela qual nos julgamos culpados pelo próprio sentimento de obsolescência que acomete a disciplina histórica. Do ponto de vista das profecias, o

${ }_{1}^{1}$ Disponível em: https://books.google.com/ngrams/info. Acesso em: 29 jul. 2019. 
digital é um futuro incontornável: tomar o seu caminho é a única maneira de garantir a sobrevivência da história e de nossa profissão.

O profético não resta solitário na relação entre os historiadores e as novas tecnologias. Para muitos nomes consagrados da historiografia, o digital não é um horizonte de otimismo, de reinvenção do nosso campo, mas uma forma de descaracterizá-lo. Nesse sentido, ainda que certos aspectos do digital sejam abraçados, as tradições humanistas devem ser garantidas, razão pela qual observam, por exemplo, práticas como a leitura e a escrita, fundamentos clássicos das ciências humanas. O historiador estadunidense Robert Darnton (2010, p. 3959), preocupado com o fenômeno do livro digital e seus efeitos sobre as bibliotecas e o mercado editorial, reconhece que o conceito de informação e a sua própria natureza sofrem uma mudança substantiva, mas não hesita em definir o livro pré-moderno (isto é, a tinta sobre o papel e as brochuras) como o mais eficaz meio de preservação do conhecimento. A tela seria incapaz de substituir os cheiros, os relevos e demais características físicas de um documento ou de uma fonte. Quando assumiu a presidência da American Historical Association, Darnton dedicou-se ao projeto Gutenberg-e, que consistia na recriação eletrônica de teses de doutorado premiadas pela instituição e em sua publicação na internet, promovendo para o grande público o acesso a monografias consagradas. ${ }^{2}$ São iniciativas como essa que revelam, em partes, o que quero dizer com "conservação" (em detrimento das profecias): o digital é encarado como uma realidade, mas não enquanto causa do abandono de princípios ou valores há muito estabelecidos pela disciplina - como é o caso do texto acadêmico e mesmo de sua escrita e leitura. Não à toa, o nome do referido projeto invoca o idealizador dos tipos móveis e da impressão moderna, a marca da tradição, referência acompanhada apenas pela letra "e", a marca do digital. ${ }^{3}$ Uma visão semelhante está em Roger Chartier (2002), que também discute o impacto das novas tecnologias sobre as normas disciplinares. No caso da digitalização do acervo de bibliotecas, especialmente antigos jornais e revistas, por exemplo, o historiador francês defende a ideia de que "por mais fundamental que seja esse projeto de digitalização, ele nunca deve conduzir à relegação ou à destruição dos objetos impressos do passado" (CHARTIER, 2002, p. 28). Há, pois, a intenção de manter vivas as heranças referentes à cultura escrita, bem como as competências clássicas das humanidades. Não se trata de uma recusa deliberada do digital, mas um olhar de desconfiança, de dúvida quanto às suas promessas.

\footnotetext{
${ }^{2}$ Disponível em: http://www.gutenberg-e.org. Acesso em: 29 jul. 2019.

${ }^{3} \mathrm{O}$ fato de que marcas analógicas dão sentido ao digital é algo recorrente. Segundo Valerie Johnson e Thomas David (2013, p. 178-179, tradução nossa), "novas tecnologias frequentemente mimetizam a apresentação ou os aspectos de velhas tecnologias. A potência dos motores de automóveis ainda é medida em cavalos; a quantidade de petróleo é calculada em barris; as lanternas, em força de velas. O botão 'salvar' em laptops e PCs consiste na figura de um singelo disquete, anos após o desaparecimento desta tecnologia; os e-readers foram concebidos para reproduzir da melhor maneira os livros, do tamanho à forma, passando por funções como virar a página [...]. Assim como o ícone do disquete, novos e-mails são indicados na barra de ferramentas por um pequeno envelope, um símbolo sem qualquer significado em termos eletrônicos".
} 


\section{DEFINIÇÕES EM ATUALIZAÇÃO}

Seja de um ponto de vista visionário, profético, seja de um ponto de vista pessimista, conservador, o digital despontou no horizonte de inquietações das ciências humanas nos últimos anos. No que se refere à sua dimensão instrumental, parece ter sido logo incorporado por pesquisadores em seus diversos ofícios. A emergência dos computadores pessoais e softwares de processamento de texto, por exemplo, permitiu-lhes o abandono das máquinas datilográficas, visto que não havia razão em permanecer produzindo trabalhos acadêmicos em um dispositivo pouco flexível, que nem sequer garante ao usuário a oportunidade de apagar uma frase mal escrita e reescrevê-la. Os e-mails, por sua vez, otimizaram a comunicação entre professores e alunos, facilitando o contato entre toda a comunidade universitária, do envio de artigos a conversas casuais. Mesmo tecnologias mais recentes, como é o caso do Google Drive, já figuram entre nossas ferramentas comuns. Não me recordo de minha última passagem pela xerox do campus, leio praticamente todos os textos das disciplinas no computador, uma vez que estão quase sempre armazenados no serviço da Google. Tendo em mente cenários como esses, me pergunto o que nos leva a crer que a história e mesmo as humanidades são intolerantes com o digital. Por que aquele meu amigo pensaria que nós estamos arrancando os cabelos em razão da internet? Afinal, não estamos sempre agregando a próxima novidade ao nosso ofício?

A relação entre as ciências humanas e o universo das tecnologias não é de todo uma novidade. Muitos pesquisadores traçam uma determinada origem das humanidades digitais a partir de projetos de ciências humanas desenvolvidos com o uso de computadores ainda em meados do século XX - quando era comum o termo humanities computing, ou "computação para as humanidades" (NYHAN; FLINN, 2016, p. 2-4). É o caso do trabalho de Roberto Busa, um homem ligado ao clero italiano que, ao final da década de 1940, foi responsável pela lematização de milhões de palavras a partir das obras de São Tomás de Aquino, um trabalho constantemente citado como a primeira grande iniciativa em humanities computing, uma espécie de primeiro namoro entre um humanista e os computadores (HOCKEY, 2004, p. 20-21). A história serial, por sua vez, conquistou um número considerável de historiadores à época. Por operar com a lógica matemática e com números complexos, a análise das chamadas "fontes seriais" era realizada com o uso de computadores, que causaram certa euforia (BARROS, 2011, p. 166). A grande maioria dessas investidas iniciais sobre os computadores aborda o digital de um ponto de vista instrumental: é uma ferramenta capaz de otimizar a pesquisa, abrir caminhos pelos quais dificilmente seguirá contando apenas com a limitada capacidade humana. O que argumentamos, no entanto, é que o digital deve ser uma problemática à parte para o pesquisador, um ponto de reflexão acerca da própria disciplina. Uma coisa é lançar mão de gadgets modernos a fim de desenvolver um trabalho em formato tradicional, outra é observá- los como um verdadeiro dilema, capaz de reconfigurar muitos dos nossos costumes enquanto pesquisadores. É certo que o digital e o analógico não anulam um ao outro, mas devem ser colocados em permanente contato, devem ser dimensões em contínua ressignificação.

A historiadora espanhola Matilde Eiroa (2018, p. 85) observa dois planos que tangenciam a relação entre a disciplina histórica e o digital: em primeiro lugar, a história na era digital - isto é, a história praticada, escrita, produzida e pensada por indivíduos 
e grupos imersos em um dia a dia atravessado pela internet, pelas redes sociais, pelos dados; em segundo, a história nascida digital - ou seja, não apenas a incorporação de tecnologias informacionais à pesquisa, mas também as manifestações humanas próprias de uma "modernidade digital" (ARAUJO; PEREIRA, 2016), dos tweets aos vídeos no YouTube, as fontes sobre as quais estarão debruçados os nossos colegas de profissão do futuro interessados nos primeiros atos do século XXI. Nesse sentido, é praticamente instintivo que a nossa comunidade faça uso de ferramentas digitais, visto ser um grupo composto por pessoas constantemente afetadas pela rede. Por mais conservador que seja um intelectual (e me refiro ao seu engajamento teórico), seria ilógico datilografar seus artigos, enviar cartas aos seus alunos ou recusar-se a manusear ambientes como o Moodle, uma iniciativa internacional de aprendizagem on-line. Não é, portanto, o mero uso de uma tecnologia que define a relação entre as ciências humanas e o digital. Se assim fosse, seríamos "todos historiadores digitais, assim como, antes, éramos todos analógicos, porque o meio pelo qual produzimos o nosso conhecimento transformou-se e é digital" (PONS, 2018, p. 32, tradução nossa). O trunfo da história digital e das humanidades digitais está na capacidade de reinventar a disciplina, ressignificar tradições que parecem perder o sentido, renovar o nosso ofício. É necessário que o digital seja um ponto de problematização em nossas reflexões, não mero aporte instrumental (NOIRET, 2015, p. 33; WELLER, 2013, p. 2).

A razão pela qual este subtópico é intitulado "definições em atualização" deve-se justamente ao fato de que as humanidades digitais e a história digital têm a potência de descontinuar os nossos fundamentos - ou de lhes atribuir novos sentidos. De volta ao atualismo, Araujo e Pereira (2019, p. 207) não escondem a assintonia que acomete as ciências humanas, que sofrem uma pressão para ser repensadas, reconfiguradas, reinstaladas, atualizadas, já que estamos sujeitos às condições de "viver em um mundo completamente virtual, [o que] pode significar um deslocamento qualitativo nessa tendência humana à formalização do tempo". Em sua origem disciplinar no século XIX, o métier científico do historiador consistia no apreço pela narrativa, pela causalidade e operacionalidade de eventos tomados como grandes marcos históricos. Para Rodrigo Turin (2009, p. 16), ele "deveria prezar pela boa forma de sua narrativa, não a tornando monótona nem excessiva. Daí a necessidade de uma criteriosa seleção e de uma ordenação talentosa, poética, dos fatos a serem narrados". Reportar-se à fundação da disciplina é quase sempre um exercício de alteridade, ainda que falemos de nossa própria profissão, de intelectuais que assumiam, guardadas as devidas proporções, a mesma identidade que nós, historiadores da virada do milênio, acatamos. Percebe-se uma série de desconexões entre o que era um historiador oitocentista e o que pode ser um historiador contemporâneo. Mesmo que a disciplina ainda opere com lógicas herdadas de sua gênese, mesmo que essas qualidades científicas ainda sejam caras a muitos dos nossos colegas e mentores, a história decididamente já não é mais aquela empresa imperial responsável pela eleição de um espírito patriótico e pela formação de uma identidade nacional (TURIN, 2009; OLIVEIRA, 2010). Praticamente expelidos pelo Estado, deixamos o status de "pedagogos da nação" responsáveis pela "ordenação talentosa e poética" das factualidades para, enfim, ante a todas as crises que nos rondam, sermos relegados à condição de um "incômodo funcionário" (TURIN, 2018, p. 194-196). É preciso reconhecer essas mudanças, refletir sobre a função do digital nesses processos. Abraçados a funções anacrônicas, correríamos o risco de sucumbir à obsolescência. 
De acordo com Byung-Chul Han (2018, p. 66, grifos do autor), "enumerar é uma categoria pós-histórica. Nem tweets nem informações se reúnem em uma narrativa. Também o mural não narra nenhuma história de vida, nenhuma biografia. Ele é aditivo, e não narrativo". Isto é, ainda que discordemos do autor no que se refere à narração de histórias de vida, o modus operandi das redes sociais parece mesmo marcado por um fluxo sucessivo de instantes que suspendem a natureza clássica de um evento histórico, de uma narrativa histórica de longa duração. Me vêm à mente as notícias urgentes - expressas em chamativas tarjas de publicações de grandes veículos de comunicação em suas redes sociais -, que pululam pelos nossos feeds, dominam momentaneamente os trending topics, apenas para que sucumbam à constante e irrefreável atualização dos acontecimentos, cedendo o seu posto de destaque entre as tendências para outros assuntos bombásticos que logo acabam submetidos ao mesmo processo fatal. Perde-se, pois, para o bem e para o mal, a qualidade narrativa dos eventos, suas causas e seus desdobramentos, diluídos em uma sucessão de urgências, nem sempre conexas, mas cada uma delas digna de um novo tumulto nas redes. Ao largo dos últimos capítulos da House of Cards nacional, como foi reinventada a política brasileira pelos fãs da série da Netflix, foram ouvidas frases como "o que há para hoje?", "todo dia uma notícia diferente", entre outras inquietações que parecem revelar essa instantaneidade dos fatos. Não à toa, o Twitter nos pergunta "o que está acontecendo agora?", o Facebook, "no que você está pensando?", e o YouTube nos convida a "transmitir ao vivo", a exibir o que está ao nosso alcance em tempo real. Han (2018, p. 107) argumenta que "a absoluta prioridade do presente caracteriza o nosso tempo. O tempo é desmontado em uma mera sucessão de presentes disponíveis. O futuro definha, aí, em um presente otimizado". São marcas de um tempo sempre à disposição do que há de mais atual, de uma "uma realidade com índice zero de inatualidade" (ARAUJO; PEREIRA, 2019, p. 160), em que a disrupção das tecnologias e o desejo pela inovação parecem ditar a maneira como projetamos o passado, o presente e o futuro.

\section{(CON)FIGURAÇÕES DA HISTÓRIA E A DISRUPÇÃO TECNOLÓGICA}

Praticamente a todo momento, seja lá onde estivermos, estamos conectados à internet. Smartphones, computadores pessoais ou notebooks, e-readers. Wi$-\mathrm{Fi}$, dados móveis, Ethernet. No ônibus, em bibliotecas, nas salas de aula, nas filas dos restaurantes ou mesmo deitado sobre a cama em meio à escuridão do quarto, podemos acessar conteúdos de humor, matérias ou artigos de jornais, filmes ou séries de televisão, mas também conteúdos relativos ao nosso trabalho - e esse é um costume que parece passar despercebido. Não são poucas as pessoas que transformam os seus perfis pessoais em feeds profissionais, compartilham notícias ou textos autorais que possam vir a interessar seus colegas e alunos, interagem com páginas ligadas ao universo do seu ofício, divulgam eventos ou pesquisas importantes na área. Esse "não limite" entre a descontração ou a casualidade e a profissão borra as fronteiras entre aquilo que se observa como trabalho e os momentos de ociosidade - ou mesmo a própria desconexão. Basta arrastar os dedos pela tela, desenhar ou digitar a senha do celular, abrir o aplicativo de um navegador de internet e iniciar a busca por livros e periódicos a fim de engordar as referências bibliográficas de 
nossos artigos e monografias. O mesmo movimento, no entanto, nos coloca diante dos mais novos episódios das nossas séries prediletas, dos trailers do momento ou da última urgência publicada pelos jornais que seguimos nas redes. Quem nunca interrompeu um momento de absoluto ócio no Facebook, quando aliviamos o cérebro da carga teórica que carregou durante um longo dia de estudos, para abrir os links compartilhados por nossos colegas e professores que, por mencionar diretamente os nossos interesses de pesquisa, nos obrigam a consumi-los de imediato? Nas palavras de Byung-Chul Han (2018, p. 65),

na era das máquinas, o trabalho, simplesmente por causa da imobilidade das máquinas, era delimitável em relação ao não trabalho. O local de trabalho, ao qual era preciso se dirigir por conta própria, se deixava separar claramente dos espaços de não trabalho. Hoje essa delimitação é completamente suprimida em algumas profissões. O aparato digital torna o próprio trabalho móvel. Todos carregam o trabalho consigo como um depósito de trabalho. Assim não podemos mais escapar do trabalho.

Vivemos, enfim, "tempos de trabalho extensos, tensos, intensos, flexíveis e imprevisíveis", à maneira de Cardoso (2016, p. 67). São expressões que se encaixam bem nas situações descritas no parágrafo anterior: do ponto de vista das relações de trabalho, as novas tecnologias alargaram as fronteiras dos nossos ofícios, dissolveram as horas dedicadas ao lazer e nos colocaram em permanente função das nossas tarefas. Lembremos de Araujo e Pereira (2019, p. 60), para quem "estar on-line significa poder dispor do outro a qualquer momento, mas também estar cada vez mais à disposição dos outros". É claro que, por outro lado - e é justo sublinhar, já que não concordamos plenamente com essa visão tão cética -, estar on-line também significa uma redefinição construtiva de uma série de características do mundo do trabalho, cada vez mais prático e, no caso de operações básicas ou fundamentais, cada vez menos burocrático. A Uber, com todos os seus problemas, é uma opção de transporte mais barata que o táxi. Os serviços de streaming, da Netflix ao Spotify, possuem preços acessíveis. O compartilhamento de conteúdo acadêmico em redes sociais é um jeito prático de se manter informado e de informar os pares e interessados em atividades universitárias. Assim ficamos sabendo do lançamento de novos livros, da publicação do último volume dos periódicos mais importantes, dos eventos que acontecerão na próxima semana. É crucial que esses meios de comunicação sejam utilizados também como canais profissionais; a sua agilidade tem muito a acrescentar ao nosso ofício. Além disso, à revelia dos autores, podemos escapar do nosso trabalho, ignorar tudo o que nos importuna em horas indevidas. Que atire a primeira pedra quem não passou reto por um post ou tweet importante a fim de preservar um dos raros momentos de relaxamento. Observações como as de Han e Cardoso são, pois, pouco ponderadas, mas denunciam um retrato com o qual precisamos lidar. Mesmo que a nossa vida digital não seja efetivamente reduzida ao trabalho sufocante, a ideia de carregá-lo consigo suscita a autorreflexão.

Outro ponto em severa transformação em uma era marcada pelas novas tecnologias é o contato do historiador com fontes históricas. A decomposição de documentos, resultado da ação do tempo e da agência humana, no caso do silenciamento deliberado de arquivos institucionais e da própria vida por parte de 
Estados de exceção, são alguns dos fatores com os quais um historiador deve lidar ao longo de sua pesquisa, atravessada por certa escassez de registros históricos. Trabalhar com temas do mundo antigo e medieval, por exemplo, é reconhecidamente uma tarefa difícil em razão dos obstáculos que minam o acesso às fontes de períodos tão distantes. Com o advento da internet, todavia, a abundância de conteúdos à disposição do pesquisador passou a energizar o seu trabalho, alimentando inúmeros caminhos que dificilmente seriam seguidos em contextos analógicos (ROSENZWEIG, 2011, p. 7). Já não dependemos do deslocamento geográfico, do gasto com passagens aéreas e hospedagens, de bolsas de estudos no exterior - ainda que, por óbvio, o financiamento de pesquisas continue sendo uma política pública de suma importância (deve, inclusive, ser expandida), e as viagens a trabalho permaneçam uma realidade. Creio que seja possível afirmar que a pesquisa se tornou mais fácil com a internet. No entanto, essa fartura, essa abundância, também é acompanhada pelo pavor do sumiço. Trata-se de certa melancolia: ante a tudo o que está disponível, esse "arquivo infinito" (FLÓREZ, 2011), acabamos por temer o retorno ao quadro de escassez. Queremos preservar tudo o que for possível sobre o nosso presente e garantir o acesso a essas informações aos nossos futuros pares, vencendo o risco de tornar a pesquisa sobre o nosso tempo uma tarefa tão complicada quanto o estudo da Antiguidade ou do Medievo. À maneira de Araujo e Pereira (2019, p. 69), "o clima predominante é de desespero, em seu sentido literal, a perda catastrófica da esperança, a dificuldade de acreditar que, nos tempos de total disponibilidade, algo possa simplesmente desaparecer". Não é necessário grande esforço, porém, para chegarmos à conclusão de que não há a menor possibilidade de registrar todo e qualquer rastro humano na internet. É inviável a preservação de cada e-mail, cada postagem em uma rede social, cada comentário, cada like, cada imagem, vídeo ou áudio enviado em chats privados no WhatsApp. No entanto, na medida em que são todas marcas do nosso tempo, na medida em que significam algo sobre a nossa contemporaneidade, talvez venham a ser importantes, em menor ou maior grau, para os futuros pesquisadores em história. Luke Tredinnick (2013, p. 42, tradução nossa) aponta para o fato de que "estamos cercados de registros históricos, não os arquivos empoeirados do passado, mas uma história viva criada em nossas interações on-line cotidianas". Pois é precisamente essa incompatibilidade que nos cerca: reconhecemos a importância dessa "história viva", mas convivemos com o seu irreparável desaparecimento. Estar ciente dessa perda é causa de um sentimento de ansiedade, como se testemunhássemos a própria história em chamas, o próprio passado (o nosso presente, ironicamente) desfazendo-se em cinzas - ou em dados corrompidos. Existe solução para esse impasse? Devemos reunir esforços a fim de preservar (com chances nulas de sucesso) toda a internet?

Segundo Turkel, Kee e Roberts (2013, p. 62-63, tradução nossa), "os métodos tradicionais de pesquisa são claramente inadequados para lidar com um arquivo instantaneamente acessível, cujos dados são legíveis por meio do computador, em crescimento exponencial e em constante registro". Ou seja, ainda que não exista de fato uma resposta mágica para a pergunta feita ao final do parágrafo anterior, há um caminho possível: não faria sentido investir em práticas conhecidas de preservação, já que não parecem as mais adequadas diante dessa realidade digital. É preciso reformular a nossa atividade, reinventar nossas competências e habilidades. Pensemos a partir da escrita de textos acadêmicos. Por que as tradicionais revisões bibliográficas - uma espécie de apanhado de todas as produções com as quais um autor deparou-se ao longo de sua pesquisa, antes restritas à consulta em bibliotecas, 
nas estantes de professores universitários ou mesmo em instituições arquivísticas ainda carregam esse sentido? Já não são efetivamente revisões, pois não é viável incorporar a um trabalho tudo o que foi e ainda é produzido sobre determinado assunto, tarefa que parecia realizável há algumas décadas, tendo em vista o acesso limitado a livros, periódicos e revistas científicas. Hoje em dia, alguns poucos cliques exibem uma enormidade de produções acerca de certa temática, e raramente (ou nunca) conseguimos acompanhá-las na íntegra. De volta ao universo dos arquivos, também seria impraticável a reunião de todos os registros existentes sobre uma pessoa ou um período presentes na internet, visto que o número de resultados de uma busca rápida no Google, por exemplo, está em constante atualização - nem sempre em "crescimento exponencial", como no caso da historiadora Renée M. Sentilles (2005, p. 138), que observou uma inconstância no número de sites sobre a artista norte-americana Adah Isaacs Menken, sujeito de sua pesquisa. Isto é, dos milhares de endereços que ela havia catalogado durante as primeiras buscas pelo nome da personagem, algumas centenas simplesmente não estavam mais disponíveis para acesso.

O argumento em favor da recriação do nosso ofício pode parecer um tanto abstrato, mas há variados exemplos que lhe garantem certa concretude. No caso do mercado e do inbound marketing, por exemplo, Marcelo Róbson Téo (2018) argumenta que o historiador poderia ser um produtor de conteúdo, atuando junto às empresas da área e incorporando valores referentes à audiência e à publicidade. Nesse sentido, as séries de televisão (não necessariamente exibidas em TVs), especialmente aquelas que retratam cenas históricas e vêm escalando em rankings de público, representam uma estratégia possível de atuação. O trabalho de consultoria histórica em novelas já é conhecido, e é certamente uma alternativa profissional interessante, mas me refiro à presença de um historiador na própria produção de seriados ou mesmo de longas-metragens, mesmo a possibilidade de ocupar cargos de referência no mercado cultural, por exemplo. Nas palavras de Téo (2018, p. 369) "é preciso trazer essa possibilidade para o interior de nossos núcleos de formação [...], incentivando a participação de cientistas sociais também em posições de decisão - e não apenas de produção junto ao mercado de conteúdo". Aproximar-se de noções de mercado, das quais estamos distantes por definição (lembremos que o ofício histórico nasceu em função do Estado imperial, e era aos seus interesses que os historiadores serviam), é uma dessas novas (con)figurações que emergem em um tempo marcado pela tecnologia e pela inovação.

Ademais, parece cada vez mais positivo o desenvolvimento de iniciativas em redes sociais, como a criação de canais e a produção de vídeos para o YouTube, de podcasts ou de páginas de compartilhamento de conteúdo especializados. Exercícios como esses representam a ruptura (mas não o abandono) com uma das tradições mais enraizadas da disciplina: a escrita, a leitura e o texto como formas absolutas da pesquisa em história ou mesmo como identidades do historiador. Por certo que a produção de vídeos, programas em áudio ou a manutenção de páginas e canais também dependem de estudos compromissados - isto é, a leitura e o consumo de trabalhos prévios que venham a auxiliar a construção dessas iniciativas e a indicação de fontes e referenciais. Práticas como essas seguem apropriadas. No entanto, o grande trunfo desses projetos é o desejo de que sejam acompanhados por um grande público - uma das razões pelas quais é crucial que a história incorpore práticas da comunicação, um campo que já está habituado às vontades de uma audiência substancial e diversa. Não são como os artigos acadêmicos, a título de exemplo, escritos para os pares 
e por eles avaliados. Projetos em redes sociais possuem outras dimensões, não se reduzem à circunferência institucional e aos ditames disciplinares. Seria decisivo estimular esses empreendimentos na própria academia, visto que, das monografias de conclusão de curso às teses de doutorado, "são poucos os estudos, advindos em sua maioria do campo da história pública e da antropologia visual, que trabalham com a linguagem audiovisual como parte da construção narrativa nas ciências humanas" (TÉO, 2018, p. 363). Felizmente, expressões como "divulgação científica" são cada vez mais comuns em nosso meio, servindo como base, inclusive, de uma série de iniciativas bem-sucedidas, como é o caso do canal Leitura OBRIGAHistória. ${ }^{4}$ Nascido em 2009 no formato de blog e parte do YouTube desde 2015, propõe-se a resenhar livros de história, divulgar autores renomados no campo das humanidades, explicar de forma sintética conceitos produzidos na academia, entre outras atividades. Hoje, o canal conta com mais de 180 mil inscritos e mais de 4 milhões de visualizações. São valores próprios de uma plataforma flexível, de rápida difusão de informações, de interação entre produtor e consumidor - e, em certo sentido, da própria dissolução dessas categorias. Dificilmente um artigo científico publicado em uma grande revista conquistaria números tão expressivos, mesmo revistas inteiramente on-line, já que o acesso é mais próximo da própria comunidade que as produz. Outra possível (con) figuração do historiador é, pois, a adoção de ferramentas comunicacionais, formas capazes de amplificar o que é feito nas universidades e o que é elaborado em grupos de pesquisa, mas também de trabalhar em conjunto com grupos que não fazem parte dessa estrutura, o que inspira projetos dotados de novos sentidos. São tarefas que demandam tempo, aprendizado e o entendimento de temas que giram em torno do público, da audiência, do mercado e de seus interesses, mas parecem caminhos bastante promissores.

Resgato a situação envolvendo a conversa casual entre este que vos escreve e os seus amigos em um daqueles encontros que os obriga a refletir sobre as decisões tomadas desde a finalização do ensino médio. "Sim, tô curtindo o curso", e tudo mais. Na passagem que dá início a este artigo, assumi que, mesmo respondendo de maneira afirmativa à questão sobre a simpatia pela minha opção profissional, me sinto preso em uma condição de incertezas, de remunerações insatisfatórias e de absoluto desprezo por parte do Estado, responsável pelo financiamento da educação pública e pela garantia de sua qualidade e de sua gratuidade. É curioso como essas novas possibilidades de atuação, essas (con)figurações do historiador sobre as quais discorremos brevemente, parecem nos dar certo fôlego, apontam uma luz no fim de um longo túnel de desesperanças. O sucesso dessas iniciativas anima toda uma geração de historiadores que iniciou a sua graduação ou a pós-graduação em meio a um processo de destruição deliberada das universidades públicas brasileiras, da ciência e da pesquisa nacionais. Por mais que seja sensato manter-se um tanto distante de entusiasmos exacerbados, parece haver um futuro disponível para os historiadores, portanto. E para a disciplina?

\footnotetext{
${ }^{4}$ Disponível em: https://www.youtube.com/channel/UCtMjnvODdK1Gwy8psW3dzrg. Acesso em: 29 jul. 2019.
} 


\section{CONSIDERAÇÕES FINAIS: HÁ RAZÃO EM DISCIPLINAR O DIGITAL?}

Um dos grandes dramas da relação entre as ciências humanas e o digital é a formação (ou não) de uma disciplina à parte que dê conta dessas discussões. Ante a emergência de novas nomenclaturas, como "humanidades digitais" ou "história digital", deve-se tomá-las como campos autônomos, assumir regras e práticas em comum, estabelecer limites de atuação? É necessário rastrear as suas origens, construir uma narrativa linear sobre a área e institucionalizá-la em departamentos e institutos? Para Nyhan e Flinn (2016, p. 18, tradução nossa), "a resposta pragmática é que as humanidades digitais configuram uma disciplina porque possuem as características de uma". Isto é, são publicadas revistas especializadas no tema, realizam-se grandes eventos e as humanidades digitais estão presentes em currículos de diferentes universidades. No entanto, mesmo sendo possível traçar um contorno disciplinar, fazê-lo é subtrair o fato de que "a própria definição do termo 'disciplina' é contestada [pelo digital]" (NYHAN; FLINN, 2016, p. 17, tradução nossa). É relevante que existam periódicos especificamente voltados às humanidades digitais; que simpósios, congressos e oficinas sejam realizados em nome de instituições acadêmicas; que sejam criadas disciplinas sobre o assunto em cursos de graduação e pós-graduação. Todavia, como alertamos anteriormente, é crucial que o digital apareça sempre como uma problemática, um ponto de reflexão sobre as ciências humanas e profissionais da área, e que não seja reduzido ao formalismo ou a uma categoria instrumental.

Em 2015, após a invasão do Museu de Mossul, no Iraque, o Estado Islâmico destruiu grande parte de um acervo milenar composto por artefatos assírios e acadianos. A ação foi gravada em vídeo e disseminada pelos próprios militantes na internet. Poucos meses depois, a artista iraniana Morehshin Allahyari idealizou um projeto de modelação digital e impressão tridimensional das peças perdidas no atentado, uma forma de recuperá-las. ${ }^{5}$ Os arquivos resultantes da iniciativa foram disponibilizados para download gratuito no site da Rhizome, uma organização artística voltada ao new media art. O trabalho da artista baseou-se nas centenas de fotografias das peças capturadas por aqueles que puderam visitar o museu antes de sua destruição. Algumas das recriações foram exibidas no Imperial War Museum, em Londres, formando parte de uma exposição acerca do ataque às culturas em decorrência de conflitos bélicos ou roubos. Na ocasião, cada impressão 3D estava acompanhada de um flash drive contendo dados sobre os objetos, uma forma de preservação daquilo que se conhecia sobre as peças antes de serem reduzidas ao pó. A arte digital e a sua propagação por meio da rede são capazes de ressuscitar obras eliminadas pela violência cultural ou mesmo pela passagem do tempo, colocando em xeque a própria ideia de que um dia deixaram de existir. Apesar do desaparecimento físico dos originais, vivem entre os dados, na internet, vivem nas imagens, nos modelos digitais e nas impressões tridimensionais (SOULELLIS, 2016). O download dos arquivos possibilita, inclusive, a reprodução desses objetos por qualquer indivíduo ou instituição que possua o equipamento necessário. Isto é, podem ser reconstruídas exatamente como eram antes da invasão ao museu. São formas de reinventar a história e o passado, de

\footnotetext{
${ }^{5}$ O portfólio de Allahyari está disponível em: http://www.morehshin.com. Acesso em: 29 jul. 2019.
} 
Ihes atribuir novos sentidos, de preservar aquilo que o tempo e o que a ação humana odienta não permitiram sobreviver. ${ }^{6}$

Como de praxe, as humanidades estão em crise. São pouco valorizadas, eliminadas de currículos universitários ou escolares, são publicamente desacreditadas e desautorizadas - inclusive por figuras ligadas ao governo federal. Acontece que o drama não se resume a problemas financeiros ou ao demérito institucional, mas estende-se aos próprios fundamentos das ciências humanas. Trata-se, também, de uma crise da "ideologia disciplinar" (AVILA, 2018, p. 38). Ou seja, o que não era comum entre as várias adversidades pelas quais as humanidades passaram anteriormente é a percepção de que, dessa vez, efetivamente correm o risco de extinção. Daí a importância de iniciativas de historiadores na internet, que, como observamos, revelam certo otimismo em relação ao nosso futuro profissional, criam expectativas positivas de futuro, e nos permitem sonhar com a possibilidade de sobreviver aos ataques sofridos. Entretanto, devem ser levados em consideração os prejuízos decorrentes da formação e do estabelecimento de um "lugar comum disciplinar", com diz Avila (2018, p. 37), da normatização dessas iniciativas. É fundamental que as recriações digitais do passado, dotadas de aspectos inovadores e estimuladas pelo que há de mais sofisticado no universo das novas tecnologias, inspirem a imaginação histórica, sempre desprendidas dos imperativos da disciplina.

\section{REFERÊNCIAS}

ARAUJO, Valdei Lopes de; PEREIRA, Mateus Henrique de Faria. Atualismo 1.0: como a ideia de atualização mudou o século XXI. Vitória, ES: Milfontes; Mariana, MG: Editora da Sociedade Brasileira de Teoria e História da Historiografia, 2019.

ARAUJO, Valdei Lopes de; PEREIRA, Mateus Henrique de Faria. Reconfigurações do tempo histórico: presentismo, atualismo e solidão na modernidade digital. Revista da Universidade Federal de Minas Gerais, Belo Horizonte, v. 23, n. 1-2, p. 270-297, jan./dez. 2016. Disponível em: https://www.ufmg.br/revistaufmg/downloads/23/13 Pereira,Mateus_Araujo,Valdei_ReconfiguracoesTempo_pags270a297.pdf. Acesso em: 25 jul. 2019.

AVILA, Arthur Lima de. Indisciplinando a historiografia: do passado histórico ao passado prático, da crise à crítica. Revista Maracanan, Rio de Janeiro, n. 18, p. 35-49, jan./jun. 2018. Disponível em: https://www.e-publicacoes.uerj.br/index.php/ maracanan/article/view/31185/23097. Acesso em: 26 jul. 2019.

BARROS, José D’Assunção. História serial, história quantitativa e história demográfica: uma breve reflexão crítica. Revista de Ciências Humanas, Viçosa, v. 11, n. 1, p. 163-172, jan./jun. 2011. Disponível em: https://periodicos.ufv.br/RCH/ article/view/3894. Acesso em: 29 jul. 2019.

\footnotetext{
${ }^{6}$ Quem me chamou a atenção para a arte digital e me apresentou ao trabalho de Morehshin Allahyari foi o historiador Pedro Telles da Silveira, na ocasião de uma roda de conversa sobre história digital organizada pelo Núcleo de Pesquisa em História (NPH) da UFRGS.
} 
CARDOSO, Ana Claudia Moreira. Direito e dever à desconexão: disputas pelos tempos de trabalho e não trabalho. Revista da Universidade Federal de Minas Gerais, Belo Horizonte, v. 23, n. 1-2, p. 62-85, jan./dez. 2016. Disponível em: https:// periodicos.ufmg.br/index.php/revistadaufmg/article/view/2756/1615. Acesso em: 7 jun. 2019.

CHARTIER, Roger. Os desafios da escrita. São Paulo: Editora Unesp, 2002.

DARNTON, Robert. A questão dos livros: passado, presente e futuro. São Paulo: Companhia das Letras, 2010.

EIROA, Matilde. El pasado en el presente: el conocimiento historiográfico en las fuentes digitales. Ayer, Madrid, v. 110, n. 2, p. 83-109, 2018. Disponível em: http:// revistaayer.com/sites/default/files/articulos/110-3-ayer110_HistDigital_APons_ MEiroa.pdf. Acesso em: 24 jul. 2019.

FLÓREZ, Jairo Antonio Melo. Historia digital: la memoria en el archivo infinito. Historia Crítica, Bogotá, n. 43, p. 82-103, jan./abr. 2011. Disponível em: https:// revistas.uniandes.edu.co/doi/pdf/10.7440/histcrit43.2011.06. Acesso em: 26 jul. 2019.

GRAFTON, Anthony. Anthony Grafton: The Future of History Books. Hnneditor, YouTube, 3 jan. 2014. Disponível em: https://www.youtube.com/ watch?v=FCGm2mGz9p0\&feature=youtu.be. Acesso em: 22 jul. 2019.

HAN, Byung-Chul. No enxame: perspectivas do digital. Petrópolis: Vozes, 2018.

HOCKEY, Susan. The history of humanities computing. In: SCHREIBMAN, Susan; SIEMENS, Ray; UNSWORTH, John (ed.). A companion to digital humanities. Hoboken: Blackwell Publishing, 2004. p. 20-39.

JOHNSON, Valerie; DAVID, Thomas. New universes or black holes? Does digital change anything? In: WELLER, Toni (ed.). History in the digital age. Londres: Routledge, 2013. p. 173-193.

LEMNY, Stefan. "L'historien de demain sera programmeur...": Emmanuel Le Roy Ladurie et les défis de la science. L'Histoire à la BnF, Paris, 28 dez. 2017. Disponível em: https://histoirebnf.hypotheses.org/1505. Acesso em: 22 jul. 2019.

NOIRET, Serge. História pública digital. Liinc em Revista, Rio de Janeiro, v. 11, n. 1, p. 28-51, maio 2015. Disponível em: http://revista.ibict.br/liinc/article/view/3634/3098. Acesso em: 25 jul. 2019.

NYHAN, Julianne; FLINN, Andrew. Computation and the humanities: towards an oral history of digital humanities. Nova York: Springer Publishing, 2016.

OLIVEIRA, Maria da Glória de. Fazer história, escrever a história: sobre as figurações do historiador no Brasil oitocentista. Revista Brasileira de História, São 
Paulo, n. 59, v. 30, p. 37-52, jun. 2010. Disponível em: http://www.scielo.br/pdf/rbh/ v30n59/v30n59a03.pdf. Acesso em: 10 jun. 2019.

PONS, Anaclet. El pasado fue analógico, el futuro es digital. Nuevas formas de escritura histórica. Ayer, Madrid, v. 110, n. 2, p. 19-50, 2018. Disponível em: http:// revistaayer.com/articulo/1280. Acesso em: 24 jul. 2019.

ROSENZWEIG, Roy. Clio Wired: The Future of the Past in the Digital Age. Nova York: Columbia University Press, 2011.

SENTILLES, Renée M. Toiling in the archives of cyberspace. In: SENTILLES, Renée M. Archive stories: facts, fictions, and the writing of history. Durham: Duke University Press, 2005. p. 136-156.

SOULELLIS, Paul. The Distributed Monument: new work from Morehshin Allahyari's 'Material Speculation' series. Rhizome, New York, 16 feb. 2016. Disponível em: https://rhizome.org/editorial/2016/feb/16/morehshin-allahyari/. Acesso em: 29 jul. 2019.

TÉO, Marcelo Róbson. Desequilíbrio de histórias parte I: um problema do campo das humanidades (?). Tempo e Argumento, Florianópolis, n. 10, v. 23, p. 358380, abr. 2018. Disponível em: http://revistas.udesc.br/index.php/tempo/article/ view/2175180310232018358/8073. Acesso em: 7 jun. 2019.

TREDINNICK, Luke. The making of history. Remediating historicized experience. In: WELLER, Toni (ed.). History in the digital age. London: Routledge, 2013. p. 39-60.

TURIN, Rodrigo. Entre o passado disciplinar e os passados práticos: figurações do historiador na crise das humanidades. Tempo, Niterói, v. 24, n. 2, p. 186-205, maio/ago. 2018. Disponível em: http://www.scielo.br/pdf/tem/v24n2/1980-542Xtem-24-02-186.pdf. Acesso em: 26 jul. 2019.

TURIN, Rodrigo. Uma nobre, difícil e útil empresa: o ethos do historiador oitocentista. História da Historiografia, Ouro Preto, n. 2, p. 12-28, mar. 2009. Disponível em: https://www.historiadahistoriografia.com.br/revista/article/view/4/4. Acesso em: 4 jan. 2019.

TURKEL, William J.; KEE, Kevin; ROBERTS, Spencer. A method for navigating the infinite archive. In: WELLER, Toni (ed.). History in the digital age. London: Routledge, 2013. p. 61-75.

WELLER, Toni (ed.). History in the digital age. Londres: Routledge, 2013. 


\begin{abstract}
AUTORIA
Bruno Grigoletti Laitano: Licenciado. Mestrando, Universidade Federal do Rio Grande do Sul, Instituto de Filosofia e Ciências Humanas, Departamento de História, Porto Alegre, RS, Brasil.
\end{abstract}

\title{
ENDEREÇO PARA CORRESPONDÊNCIA
}

Avenida Osvaldo Gonçalves Cruz, 491, 91760-060, Porto Alegre, RS, Brasil.

\section{ORIGEM DO ARTIGO}

Artigo escrito ao longo de discussões realizadas em disciplinas cursadas no primeiro semestre do curso de mestrado, em eventos acadêmicos e conversas informais que tangenciaram o assunto abordado no trabalho. O tema também aparece em subcapítulos da dissertação, que será apresentada ao Programa de Pós-Graduação em História da UFRGS no final de 2020.

\section{AGRADECIMENTOS}

Agradeço a todos aqueles que, em espaços acadêmicos ou não, me estimularam a pensar sobre os problemas dissecados no texto. Sou grato, em especial, a Caroline Silveira Bauer, minha orientadora, com quem divido dramas acadêmicos desde os primórdios da graduação.

\section{FINANCIAMENTO}

Este artigo foi financiado com bolsa de mestrado da Coordenação de Aperfeiçoamento de Pessoal de Nível Superior (CAPES).

\section{APROVAÇÃO DE COMITÊ DE ÉTICA EM PESQUISA \\ Não se aplica.}

\section{CONFLITO DE INTERESSES}

Não houve conflito de interesses.

\section{LICENÇA DE USO}

Este artigo está licenciado sob a Licença Creative Commons CC-BY. Com essa licença você pode compartilhar, adaptar e criar para qualquer fim, desde que atribua a autoria da obra.

\section{PUBLISHER}

Universidade Federal de Santa Catarina. Programa de Pós-Graduação em História. Portal de Periódicos UFSC. As ideias expressadas neste artigo são de responsabilidade de seus autores, não representando, necessariamente, a opinião dos editores ou da universidade.

\section{EDITORES}

Flávia Florentino Varella (Editora-chefe)

Rodrigo Bragio Bonaldo

\section{HISTÓRICO}

Recebido em: 25 de agosto de 2019

Aprovado em: 23 de dezembro de 2019

Como citar: LAITANO, Bruno Grigoletti. (Con)figurações do historiador em um tempo marcado pela disrupção tecnológica. Esboços, Florianópolis, v. 27, n. 45, p. 170-186, maio/ago. 2020. 